\title{
Transient Load Share Management of a Diesel Electric Hybrid Powertrain for Ship Propulsion
}

\section{Sotiris K. Topaloglou}

Laboratory of Marine Engineering (LME),

National Technical University of Athens,

Zografos, Greece

E-mail: s.topaloglou@gmail.com

\section{George Papalambrou}

Laboratory of Marine Engineering (LME),

National Technical University of Athens,

Zografos, Greece

E-mail: george.papalambrou@lme.ntua.gr

\section{Konstantinos Bardis}

Laboratory of Marine Engineering (LME),

National Technical University of Athens,

Zografos, Greece

E-mail: kwstasbardis@gmail.com

\section{Nikolaos Kyrtatos}

Laboratory of Marine Engineering (LME),

National Technical University of Athens,

Zografos, Greece

E-mail: nkyrt@1me.ntua.gr

\begin{abstract}
:
In this paper, a transient load share methodology for a hybrid diesel electric marine propulsion system is presented. Aim of the system is the performance enhancement and reduction of gaseous emissions during low-load transient operation. The controlled variable is $\lambda$ while the manipulated variable is the torque from the electric motor regulated by a frequency inverter.

The model for the $\lambda$ behavior is based on experimental identification while $\lambda$ values in feedback loop come from an actual and a virtual sensor, the later based on first principles modeling. A nominal model is used for the synthesis of a robust $H_{\infty}$ controller for the controlled variable regulation.
\end{abstract}

